\title{
Design and Analysis of Biquad Patch Antenna with Different Hard Substrates for UWB Applications
}

\author{
T.Jayanthy ${ }^{\mathrm{a}}$, I.Rexiline Sheeba ${ }^{\mathrm{b}}$ \\ ${ }^{a}$ Principal, Panimalar Institute of Technology, Chennai 602103, India \\ ${ }^{b}$ Research Scholar, Sathyabama University, Chennai 600119, India
}

\begin{abstract}
An innovative double Biquad patch antenna was introduced. It consists of two quad patch together. good directivity was achieved due to the corner reflector effect used in this design. The radiating elements are of four square with the side length equal to $1 / 4$ mid band wavelength. The theoretical beam width can be varied widely with the reflection plane size and shape. Vertical Polarization is achieved from the position of orientation of the biquad.Biquad patch was implemented in microstrip antenna with three hard substrates such as Arlon, Neltec, and Fr4, High directivity,good gain and low return loss was achieved, and the resonant frequency obtained is from $5-10 \mathrm{GHz}$, which is suitable for UWB application and the simulation was performed using HFSS.
\end{abstract}

Index Terms: Patch antenna, Directivity, hard substrates, UWB

(C) 2017 Published by MECS Publisher. Selection and/or peer review under responsibility of the Research Association of Modern Education and Computer Science

\section{Introduction}

An wireless technology used to transmit large amount of datas over wide spectrum of frequency band for a short distance with low power. Which has the capacity to carry signals over obstacles which tend to reflect signal. FCC approved the commercial use of ultra wideband in 2002.Low dielectric constant[2] with hard substrates can increase bandwidth with low and coupling of patches are also possible. Since UWB antennas offers low power operation and has low radiated power it was attractive for battery operated body worn devices.UWB antennas afford omnidirectional radiation pattern. Microstrip patch antenna in UWB application faces many limitations such as low gain, low efficiency and narrow bandwidth. An excellent alternative for handheld device in UWB application is patch antenna, antenna length determines the gain and directivity.

Ultra wideband is a technology for transmission of data using techniques which cause spreading of radio

* Corresponding author: T.Jayanthy, I.Rexiline Sheeba, 04426491113

E-mail address: jayanthymd@rediffmail.com 
energy over a wide frequency range from $3.1-10.6 \mathrm{GHz}$, with power spectral density as low.UWB Technology has many compensation in high data transmission rates and it is well beyond with the deployed technologies such as Wimax, $802.11 \mathrm{a}, \mathrm{b}$, .UWB is a type of transmission, occupies a very wide bandwidth in GHz. Also it enables to carry the data rate of Gigabits per second [3].

Ultra-wideband characteristics are well-matched to short-distance applications, such as PC peripherals.UWB systems are inclined to be short-range indoor applications. Due to the short period of UWB pulses, it is easier to wangle high data rates; data rate may be exchanged for range by combining pulse energy per data bit (with integration or coding techniques). High-data-rate UWB may permit wireless screens, the efficient transfer of data from, wireless printing of digital pictures from a camera without the need for a personal computer and file transfers between handsets and handheld portable devices such as portable media players[5]. UWB is used for real-time location systems, its precision competences and low power make it well-suited for radio-frequencysensitive surroundings. short broadcast time also an one more feature of UWB. The advantages of the patch antenna and the applications are in the various fields such as in the medical applications, satellites and in the military systems rockets, aircrafts missiles etc. Microstrip antennas are spreading widely in all the fields and areas ,also in the commercial aspects due to their low cost of the substrate material and the fabrication.

In this research work the patch and the feed achieves a good matching. To improve bandwidth three hard substrates have been introduced with low dielectric constant .Thick substrate result in inductance and an increased length is introduced by the design of coaxial feed.

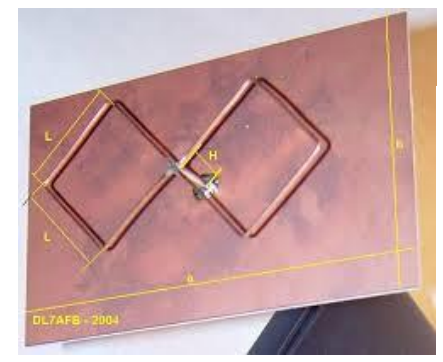

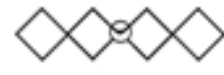

vertically polarised

horizontally polarised

Fig.1. (a).Biquad Antenna (www.Antenna Theory.com) (b).Double Biquad structure

The objective of this work is to design a coaxial feed microstrip double biquad patch and to study the effects of various antenna parameters like gain, efficiency, return loss ,radiation pattern etc. with respect to three different substrates with their different dielectric constants (cr).

\section{Antenna Design constraint includes Bandwidth and feeding Techniques}

Proper impedance matching should be achieved to the feed line for well-organized emission. In the probe feed inner conductor of a co-axial cable pierce in to the substrate and is fused to the patch which plays the major role for radiation. Although the input impedance determined by the inset length. Thick and hard substrate introduces limited increase in bandwidth. However large inductance is introduced by the length of the probe feed. When Low permittivity substrate material is used, it can increase the bandwidth of operation which leads to the increase in dimensions, leads the difficulty for use in handheld devices. High permittivity of the substrate material increases the $\mathrm{Q}$ of the antenna direct to reduction in impedance Bandwidth.

Resonant frequency and patch length related to $\mathrm{f}_{\mathrm{c}}$

$$
\mathrm{f}_{\mathrm{c}} \cong \frac{c}{2 L \sqrt{\varepsilon r}}=\frac{1}{2 L \sqrt{\varepsilon} 0 \epsilon r \mu 0}
$$

Length of the Antenna is given by 


$$
\begin{aligned}
& \mathrm{L} \cong \frac{1}{2 \mathrm{fc} \sqrt{\varepsilon} 0 \varepsilon r \mu 0} \\
& \mathrm{~B} \alpha \frac{\varepsilon r-1}{\varepsilon r^{2}} \frac{W}{L} h
\end{aligned}
$$

Effective constant (pozar et.al,1995)

$$
\begin{aligned}
& \varepsilon \text { reff }=\frac{(\varepsilon r+1)}{2}+\frac{(\varepsilon r-1)}{2} \sqrt{\left[1+12 \frac{h}{w}\right]} \\
& \mathrm{L}=\frac{\lambda 0}{2}-2 \Delta \mathrm{L}
\end{aligned}
$$

Increased Width of substrate in antenna design plays major function. By using low permittivity substrates Bandwidth can be increased. Few important parameters such as, dielectric substrate height (h), Resonant frequency and relative permittivity ( $\left.\varepsilon_{\mathrm{r}}\right)$ controls the antenna properties. Furthermore patch length controls the resonant frequency. Longest path on the Patch controls the frequency of operation to be low. And width controls the radiation pattern and input impedance wider the patch and lower the input impedance.

Substrates play an important role in deciding the various parameters of the antenna. The parameters will vary with the permeability of the substrate. So, the antenna was implemented on three different substrates like Fr4, Neltec, and Arlon and the parameters like return loss, directivity, efficiency and gain was measured for each substrate and is compared with the same double Biquad patch.

\section{Software Requirement}

The design of a simple biquad and a double biquad patch antenna using HFSS was shown in figure 2.(a)\&(b) and the results are obtained from the simulations.
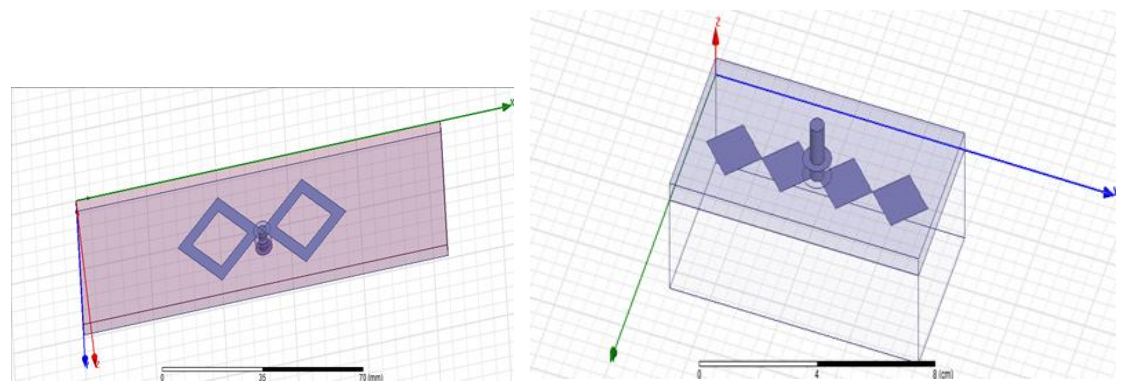

Fig.2(a). Biquad patch using HFSS (b).Double Biquad patch using HFSS

The microstrip patch design is achieved by using coaxial feed technique. For conventional microstrip line fed antennas with a thick substrate [6], the major problem associated is impedance matching. To solve this problem trial and error method is used to match perfectly. This behaviour makes good impedance matching over a wide bandwidth. The feed point is obtained by trial and error method to obtain a better return loss value. The centre frequency in the return loss is minimum, the bandwidth can be calculated. The return losses of various substrates are given below.

\section{Simulation Results Using Fr4 Substrate}



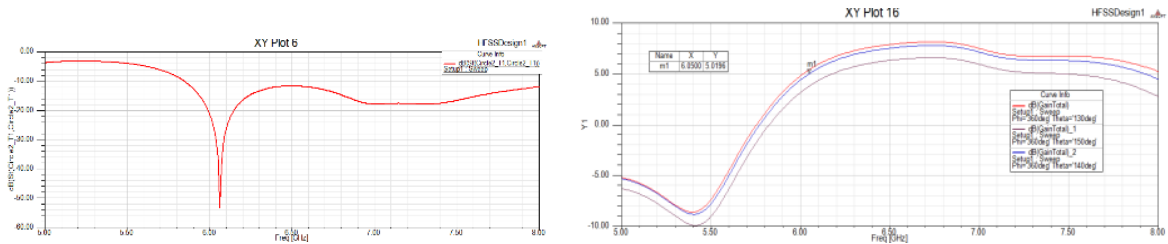

Fig.3 (a). Return Loss Using Fr4 Substrate (b) Gain

Figure3. (a)\& (b) shows that the antenna is found to be operating in the frequency range of 5.85 to $8.15 \mathrm{GHz}$ with the centre frequency at $6.06 \mathrm{GHz}$ with the minimum return loss of about $-53 \mathrm{db}$. The gain of the antenna was found to be $5 \mathrm{db}$. The figure shows different values of gain for different values of theta and phi.
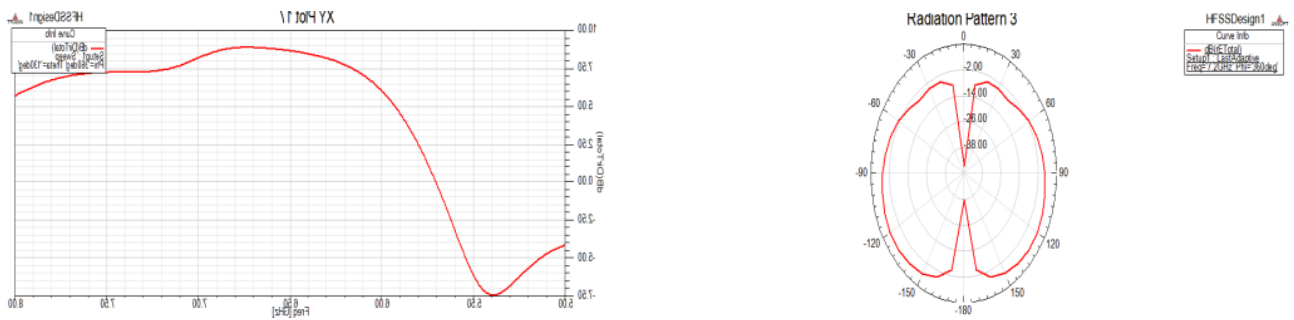

Fig.4(a). Directivity Using Fr4 Substrate (b).Radiation Pattern

Fig.4( a)\&(b) shows the directivity and radiation pattern of the double biquad patch antenna on fr4 substrate was found to be 9.2 .

\section{Simulation Results Using Neltec Substrate}
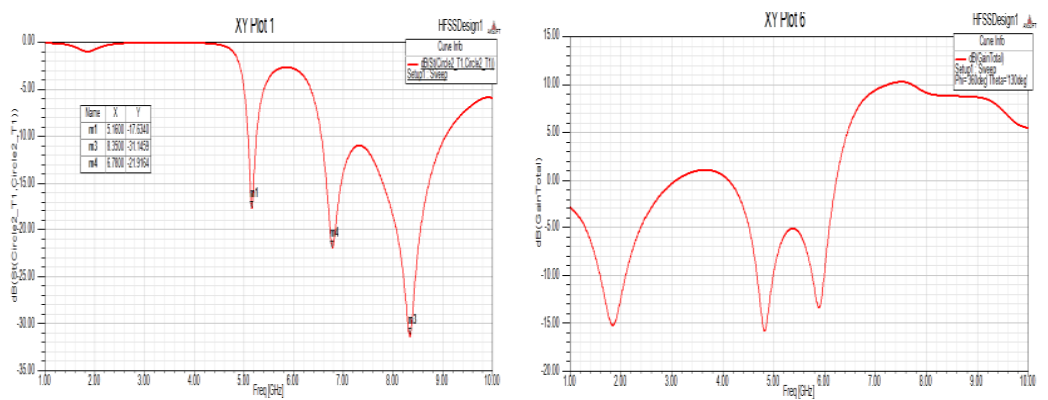

Fig.5(a) Return Loss Using Neltec Substrate Fig.(b). Gain Using Neltec Substrate

Fig.5.(a) \&(b) shows the Return loss and Gain the antenna was found to operate at three different frequencies which are $5.16 \mathrm{GHz}, 6.78 \mathrm{ghz}$ and $8.35 \mathrm{GHz}$ with a minimum return loss of about $-34 \mathrm{db}$ at $6.78 \mathrm{GHz}$. The peak gain was found to be $9.5 \mathrm{db}$ with more than $3 \mathrm{db}$ variation. 

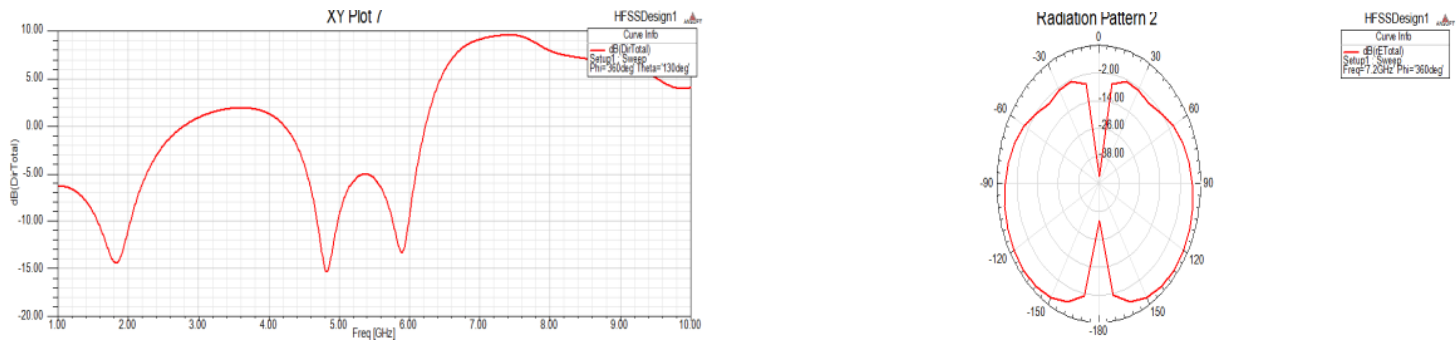

Fig.6 (a). Directivity using NelTec Substrate Fig.(b).Radiation pattern using NelTec substrate

The above figure 6.(a)\&(b)shows that the directivity and Radiation pattern, it was found to be $9.4 \mathrm{db}$ and hence the efficiency of about $94 \%$ is obtained. The values of directivity are varied in accordance with the values of theta and phi.

\section{Simulation Results Using Arlon Substrate}
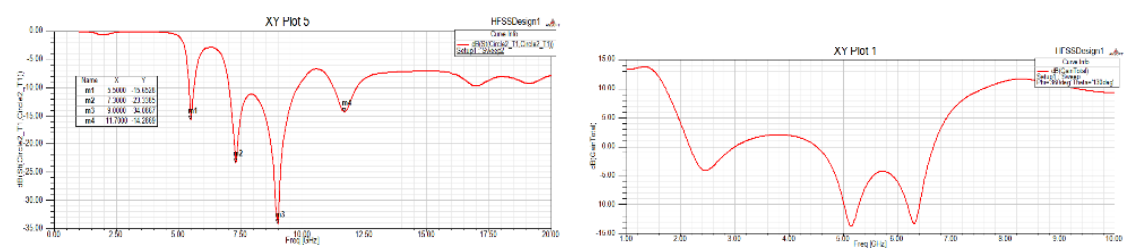

Fig.7(a).Return Loss Using Arlon Substrate Fig.(b).Gain Using Arlon Substrate

Figure 7.(a) \&(b) Shows Return Loss and Gain using ARLON substrate and the operating frequencies at 5.2 $\mathrm{GHz}, 8.8 \mathrm{GHz}, 7.3 \mathrm{GHz}, 11.6 \mathrm{GHz}$ with a minimum return loss of about $-35 \mathrm{db}$ at the frequency $8.87 \mathrm{GHz}$. The antenna has a gain of about $12 \mathrm{db}$ with more than $5 \mathrm{db}$ variations.
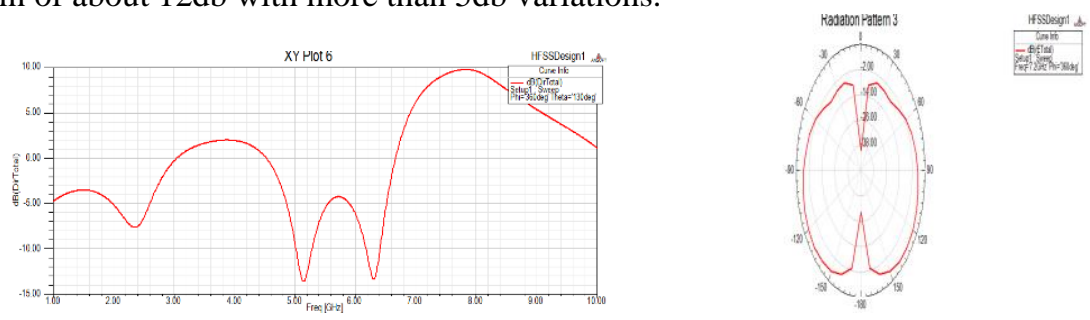

Fig.8 (a) Directivity Using Arlon Substrate Fig. (b).Radiation Pattern Using Arlon

Figure8.(a)\&(b) shows that the peak directivity and Radiation Pattern it is about $10 \mathrm{db}$ and hence it has a very low efficiency of about $86 \%$. The values of directivity is dependent on the values of theta and phi. From the simulated results following tabulation was made. The parameters return loss, gain, directivity and efficiency for three substrates fr4, Neltec, and Arlon substrates are compared to find the best suitable substrate with high gain, low return loss and good efficiency. 
Table.1.Comparison of performance in Various Substrates

\begin{tabular}{|c|c|c|c|c|c|c|}
\hline Substrate & $\begin{array}{l}\text { Relative } \\
\text { permeability } \\
(\mathrm{\varepsilon r})\end{array}$ & Resonent freq in GHz & Return loss in dB & $\begin{array}{l}\text { Efficiency } \\
(\%)\end{array}$ & Gain (dB) & $\begin{array}{l}\text { Directivity } \\
(\mathrm{dB})\end{array}$ \\
\hline Arlon & 3 & $5.2,8.87,7.3,11.6$ & -34 & 83 & 12 & 10 \\
\hline FR4 & 4.4 & 5.85 to 8.15 & -53 & 91 & 8.2 & 9 \\
\hline Neltec & 3.4 & $5.16,6.78,8.35$ & -35 & 94 & 9.4 & 10.1 \\
\hline
\end{tabular}

From Table .1.It is observed that the proposed Double biquad patch antenna operates in the frequency range of about 5 to $11 \mathrm{GHz}$ which is suitable for UWB application.. The radiation pattern of the antenna on various substrates remains the same. The gain, efficiency and the directivity of the antenna on these different types of substrates is also found to be stable. The following Chart gives the performance of Return loss.

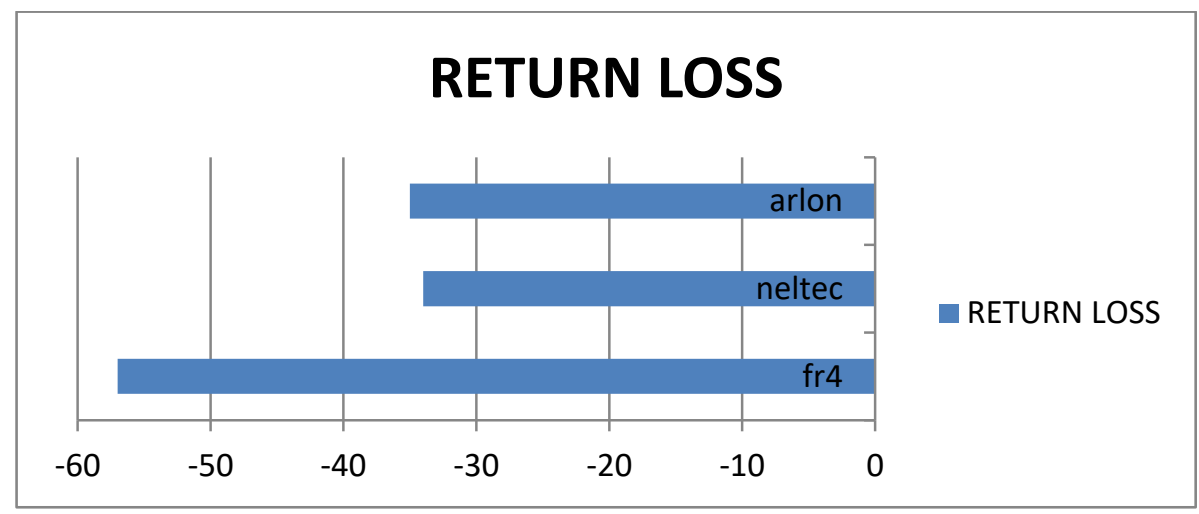

Fig.9. Comparison Chart For Return Loss On Various Substrate

Figure (9). Shows the comparison of return loss parameter of the antenna for the three substrates namely Arlon, Neltec and fr4. The minimum return loss of around $-53 \mathrm{db}$ is found for fr4 substrate and the return loss of the other two substrates are nearly $-35 \mathrm{db}$.

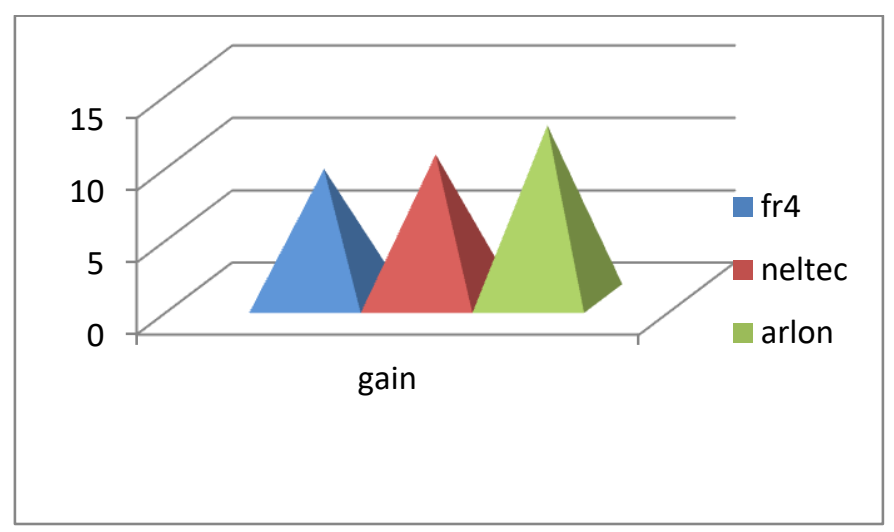

Fig.10. Comparison Chart For Gain On Various Substrate 
Figure.(10). Shows the comparison of gain of the antenna on the above mentioned substrates. The gain of the antenna on all the three substrates are relatively good and it is around $9 \mathrm{db}$.

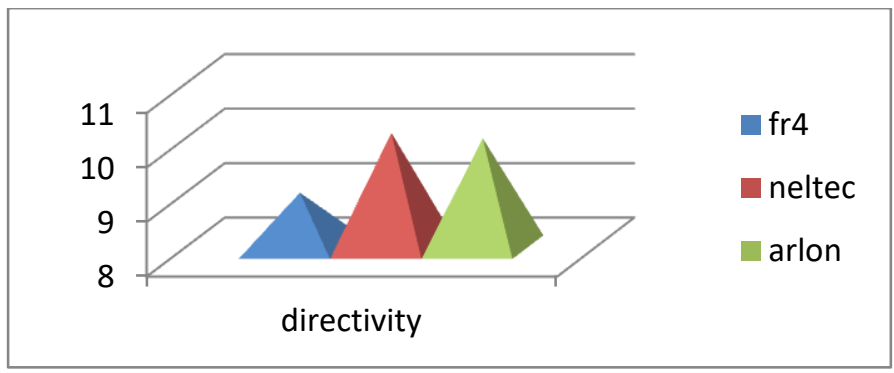

Fig.11. Comparison Chart for Directivity on Various Substrates

Figure (11). Shows the directivity of the antenna on various above mentioned three substrates. It indicates that the directivity is low for FR4 substrate when compared with the other two substrates.

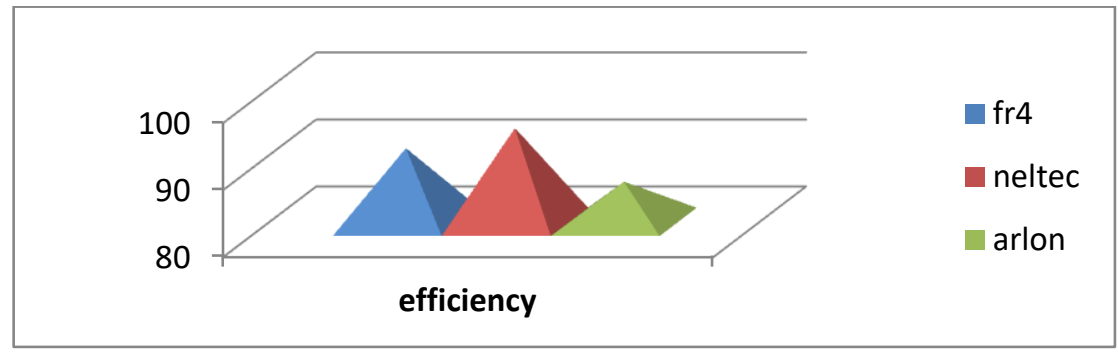

Fig.12. Comparison Chart For Efficiency on Various Substrate

Figure (12). Shows the comparison of efficiency of the antenna on those three substrates. The efficiency is quite low for the Arlon substrate while the efficiency of other two substrates is around $90 \%$.

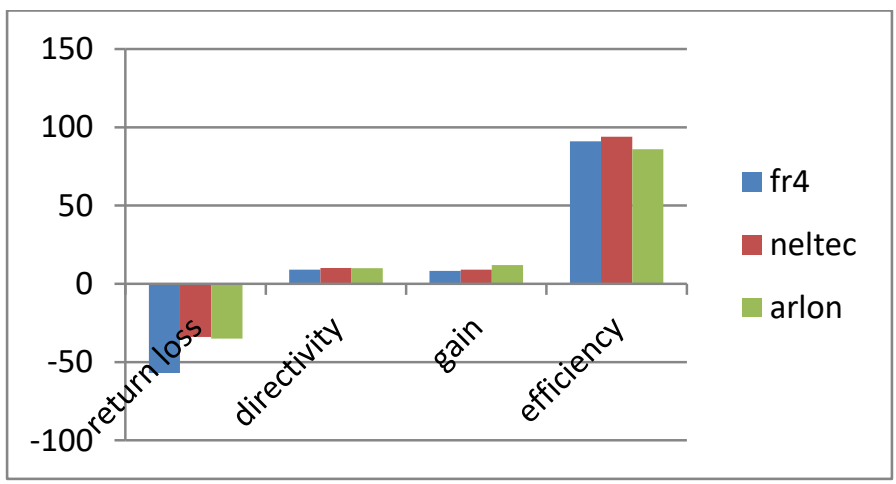

Fig.13. Overall Comparison Chart on Various Substrate

The figure (13). Shows the overall comparison of all the parameters on the three substrates which are Arlon, Neltec, and fr4 substrate. The comparison shows that the microstrip double biquad antenna works efficiently on all the three substrates with comparatively good gain, directivity and low return loss. 


\section{Conclusions}

The design of simple double biquad patch antenna has been simulated using HFSS . The simulation results are satisfied and fabrication is possible. The choice of the resonant frequency of the microstrip antenna depends on their dimension, the substrate material and its thickness and the feed line. Due to high gain and directivity the transmission of data is increased. To improve directivity and gain to a particular direction this type of patch antenna is preferred. A small variation of each of these parameters influences the resonant frequency, Reduction of size and the increase of bandwidth establish a major axis of novel conception for the practical ultra wide band applications of the microstrip antenna. The microstrip double biquad antenna can be implemented on other substrates and the variation in antenna parameters can be found.

\section{References}

[1] Bahl, R. E. and P. Bhartia, "Microstrip Antennas", Artech House, Dedham, MA, 1980.

[2] Yashar Zehforoosh, Changiz Ghobadi, and Javad Nourinia Urmia University, Iran," Antenna Design for Ultra Wideband Application Using a New Multilayer Structure, PIERS ONLINE, VOL. 2, NO. 6, 2006.

[3] Mustafa Abu Nasr1, Mohamed K. Ouda and Samer O. Ouda" Design of Star-Shaped Microstrip Patch Antenna for Ultra Wideband (UWB) Applications"International Journal of Wireless \& Mobile Networks (IJWMN) Vol. 5, No. 4, August 2013.

[4] Ansoft Corporation, user's guide: High Frequency Structure Simulator V10.

[5] Lim, K.-S., M. Nagalingam, and C.-P. Tan, 2008' Design and construction of microstrip uwb antenna with time domain analyses, Progress In Electromagnetics Research M, Vol. 3, 153.

[6] Sahaya Anselin Nisha, A. and T. Jayanthy "Analysis of Various parameter of Square Notch Patch Antenna using Energy Band Gap And Defected Ground Structure”'International journal of microwave and optical Technology" vol.6,no.7,2011.

[7] Yang, T. and W. A. Davis, 2004,' Planar half-disk antenna structures for ultra wideband communications', Proc. IEEE Int. Symp AntennasPropagation, Vol 3, 2508.

[8] "M. H. Diallo Yaccoub, Achraf Jaoujal, Mohammed Younssi, Ahmed El Moussaoui, and Noura Aknin Rectangular Ring Microstrip Patch Antenna for Ultra-wide Band Applications"International Journal of Innovation and Applied Studies ISSN 2028-9324 Vol. 4 No. 2 Oct. 2013, pp. 441-446, 2013 Innovative Space of Scientific Research Journals.

[9] W. Mazhar1; 2, M. A. Tarar2, F. A. Tahir2, Shan Ullah2, and F. A. Bhatti1Compact Microstrip Patch Antenna for Ultra-wideband Applications, PIERS Proceedings, Stockholm, Sweden, Aug. 12\{15, 2013$\}$.

[10] Sahaya Anselin Nisha, A. and T. Jayanthy "Design of hybrid coupler connected square Array patch Antenna for Wi-Fi Application” Journal of Computer Science 2012, 8 (11), 1830-1833

[11] Harleen Kaur , Balwinder Singh Dhaliwal, "Numerical Analysis of Slot Position of Rectangular U Slot Microstrip Patch Antenna" I.J. Wireless and Microwave Technologies, 2016, 3, 29-39 Published Online May 2016 in MECS 10.5815/ijwmt.2016.03.04.

[12] Sheikh Dobir Hossaina, K. M. Abdus Sobahanb , Md. Khalid Hossainc*et.al , "A Rectangular Microstrip Patch Antenna for Wireless Communications Operates in Dual Band" I.J. Wireless and Microwave Technologies, 2016, 5, 35-44 Published Online September 2016 in MECS, DOI: 10.5815/ijwmt.2016.05.04. 


\section{Authors' Profiles}

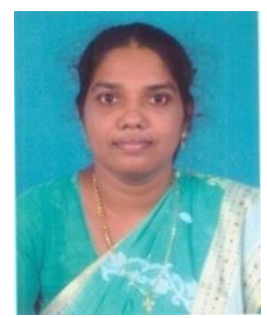

T.Jayanthy received doctorate degree in the field of Microwaves in Sathyabama University in 2007, B.E and M.E degree from Madurai Kamaraj University in 1990 and 1993 respectively. She has totally 24 years teaching experience. She was working as Professor in Electronics and communication department in Sathyabama University. She is currently working as Principal in Panimalar Institute of Technology. She is a fellow of IETE, life member of Society of EMC Engineers and a life member of Engineering science Association. She has published several papers in international/national journal and conferences. She has written books named as Microwave Engineering, optical Engineering and transmission lines and waveguides. Her fields of interests are Electromagnetics, Microwaves and Antennas.

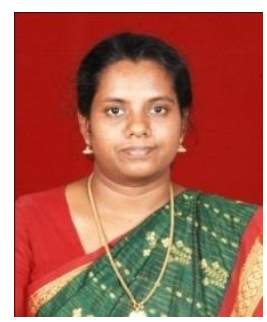

Rexiline Sheeba received Bachelor of Engineering., degree in Electronics and Communication Engineering from Manonmaniam Sundaranar University in 2003. And her Master degree in Karunya University in 2006.She is currently pursuing the Ph.D. degree in Antennas and Wave propagation in Sathyabama University, Chennai. She is also an assistant Professor in the same University. She has published Research articles in national, international Journals and conferences. Her current interests include Communications,VLSI and antenna design,Bioelectromagnetism, in various applications

How to cite this paper: T.Jayanthy, I.Rexiline Sheeba,"Design and Analysis of Biquad Patch Antenna with Different Hard Substrates for UWB Applications", International Journal of Wireless and Microwave Technologies(IJWMT), Vol.7, No.3, pp.58-66, 2017.DOI: 10.5815/ijwmt.2017.03.06 